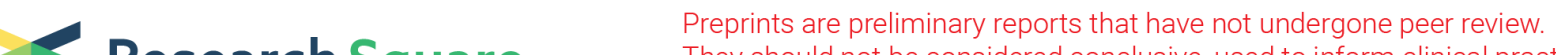 Research Square They should not be considered conclusive, used to inform clinical practice, or referenced by the media as validated information.
}

\section{Palmitate Enhances The Efficacy of Cisplatin And Doxorubicin Against Human Endometrial Carcinoma Cells}

\section{Zihsyuan Wu}

National Defense Medical Center

Shinming Huang

National Defense Medical Center

Yuchi Wang ( $\nabla$ yuchitsgh@gmail.com )

National Defense Medical Center https://orcid.org/0000-0002-1019-019X

Research article

Keywords: Lipotoxicity, Palmitate, Endometrial cancer, Adjuvant chemotherapy

Posted Date: October 1st, 2021

DOI: https://doi.org/10.21203/rs.3.rs-900527/v1

License: (c) (i) This work is licensed under a Creative Commons Attribution 4.0 International License.

Read Full License

Version of Record: A version of this preprint was published at International Journal of Molecular Sciences on December 22nd, 2021. See the published version at https://doi.org/10.3390/ijms23010080. 


\section{Abstract}

Background: Endometrial cancer is the most common gynecological cancer worldwide. Overexpression of fatty acid synthase is a common molecular feature of a subgroup of sex steroid-related cancers associated with poor prognoses, including endometrial cancers. The saturated fatty acid palmitate reportedly induces lipotoxicity and cell death by inducing oxidative stress in many cell types. Here, we explored the effects of palmitate combined with doxorubicin or cisplatin in the HEC-1-A and RL95-2 human endometrial cancer cell lines.

Methods: Endometrial cancer cells were cultured with in vitro and treated with palmitate, doxorubicin, and cisplatin. Cell metabolic activity and combination index was measured using MTT assay. Protein expression was assessed with western blotting. Flow cytometry was used to examine the cell cycle profiles, cell proliferation, apoptosis, ROS, mitochondria membrane potential, and mitochondrial mass. Immunocytochemistry was used to investigate the mitochondrial morphology.

Results: Physiological concentrations of exogenous palmitate significantly increased cell cycle arrest, DNA damage, autophagy and apoptosis in both RL95-2 and HEC-1-A cells. It also increased the chemosensitivity of both cell types. Notably, we did not observe that palmitate lipotoxicity reflected increased levels of reactive oxygen species, suggesting palmitate acts via a different mechanism in endometrial cancer.

Conclusion: This study provides a potential therapeutic strategy in which palmitate is used as an adjuvant in the treatment of endometrial cancer.

\section{Introduction}

Cancer of the endometrium is the most frequently occurring gynecological cancer (Torre, et al., 2017). In recent years, both the incidence of endometrial cancer and its associated mortality have been increasing rapidly around the world. In Taiwan, for example, the incidence of endometrial cancer now exceeds that of both cervical and ovarian cancer (Tseng, et al., 2017). Risk factors for endometrial cancer include endometrial hyperplasia, menopausal estrogen, obesity, nulliparity, polycystic ovary syndrome, high cumulative doses of tamoxifen, diabetes and genetic factors, among others (Felix, et al., 2018). Based on their clinical pathogenic mechanisms, endometrial cancers have been classified into two major types: type I is estrogen-dependent and related to hormonal imbalances, while type II is non-estrogen-dependent (Sherman, 2000). Most patients with endometrial cancer are type I and associated with excessive use of estrogen, endometrial hyperplasia, or obesity. Type II tumors are usually more common in obese women who may have endocrine or metabolic disorders, and they are also related to atrophic endometrium (Murali, et al., 2014). There are a number of treatments for endometrial cancer, including surgery, chemotherapy, radiation, and hormone therapy. Stage, histology, and tumor characteristics are the most important determinants guiding therapeutic strategy (Cosgrove, et al., 2021). Statistics indicate that while most patients with low-grade tumors can be cured through surgery and chemotherapy, the survival rate 
among patients with advanced or recurrent endometrial cancers is very low. The main reason is resistance of the cancer cells to chemotherapy and the limited treatment methods currently available. Further research is needed to improve existing therapies to address this challenge.

Palmitate is the most abundant saturated fatty acid, accounting for $70-80 \%$ of total plasma free fatty acids. It can be supplied in food or synthesized endogenously via de novo lipogenesis (DNL) (Ly, et al., 2017), which is a tightly controlled process that converts carbohydrates into the fatty acids used to synthesize triglycerides or other lipid molecules for membrane biosynthesis and energy storage (Song, et al., 2018). Fatty acid synthase (FAS) is the key rate-limiting enzyme in DNL and converts malonyl-CoA to palmitic acid, the primary fatty acid product in DNL. Palmitate is subsequently elongated and desaturated to produce complex fatty acids, including stearic acid, palmitoleic acid, and oleic acid.

In normal tissues, palmitate content is regulated to within a range of concentrations, and ingestion does not significantly affect palmitate levels in tissues (Song, et al., 2017). The mechanism by which tissue palmitate concentrations are strictly regulated may be primarily related to maintaining normal homeostasis with tissues, including maintenance of the physical properties of membranes and the biosynthesis of palmitoylethanolamide (Carta, et al., 2017). However, under certain physiological and pathological conditions and nutritional factors, DNL may be strongly induced, increasing tissue palmitate levels and disrupting its regulation (Wilke, et al., 2009). These can lead to dyslipidemia, hyperglycemia, and accumulation of ectopic fat, which can in turn lead to atherosclerosis, neurodegenerative diseases, cancer, and other diseases related to lipid physiology and pathology (Carta, et al., 2017).

Palmitate exerts adverse effects in part by inducing reactive oxygen species (ROS) generation, which leads to lipotoxicity associated with endoplasmic reticulum stress, mitochondrial dysfunction, and cell death in a number of cell types, including adipocytes (Davis, et al., 2009), glomerular podocytes (Xu, et al., 2015), pancreatic $\beta$ cells (Sato, et al., 2014), cardiomyocytes (Joseph, et al., 2016), endothelial cells (Yamagishi, et al., 2002), vascular smooth muscle cells (Brodeur, et al., 2013) and hepatocytes (Meyn, et al., 1986). However, contradictory findings from one study indicates that palmitate-induced pancreatic $b$ cell death is not caused by ROS (Choi, et al., 2011). Consequently, the mechanism by which palmitate mediates ROS production remains unclear.

Additionally, recent studies into the role of palmitate in cancer has shown that compared to normal breast and some tumor cells, HER2/neu-positive breast cancer cells show significantly increased fatty acid synthesis and storage. And when physiological doses of exogenous palmitate are added, fatty acid synthesis is disrupted, leading to CHOP (C/EBP homologous protein)-dependent apoptosis (Baumann, et al., 2016). Palmitate also induces reductions in the mitochondrial membrane potential (MMP) and release of cytochrome c into the cytosol in MDA-MB-231 cells (Hardy, et al., 2003). Moreover, it has been observed in patients with endometrial cancer that, compared to benign endometrial tumors, malignant tumors are enriched in glycolytic and lipogenic metabolic pathways and depend on this metabolism for survival (Byrne, et al., 2014). However, the effect of palmitate in endometrial cancer remains incompletely understood. 
Here, we used the RL95-2 and HEC-1-A endometrial cancer cell lines to investigate the mechanism(s) underlying palmitate cytotoxicity and its effect on the cells' responsiveness to cisplatin and doxorubicin. Our aim was to shed light on the lipotoxicity of palmitate and a potential strategy for the treatment of endometrial cancer.

\section{Materials And Methods}

\section{Cell culture and reagents}

The RL95-2 (ATCC $® C R L-1671^{\text {TM }}$ ) and HEC-1-A (ATCC $® H T B-112^{\text {TM }}$ ) human endometrial carcinoma cell lines were purchased from the American Type Culture Collection (Manassas, VA, USA). RL95-2 cells were cultured in Dulbecco's Modified Eagle's Medium Nutrient Mixture F-12 (DMEM/F12) supplemented with $10 \%$ fetal bovine serum (FBS), $0.005 \mathrm{mg} / \mathrm{ml}$ insulin, and $1 \%$ penicillin-streptomycin (Thermo Fisher Scientific, Waltham, MA, USA). HEC-1-A cells were cultured in McCoy's 5A medium supplemented with $10 \%$ FBS and $1 \%$ penicillin-streptomycin. Doxorubicin, cisplatin, sodium palmitate, 2',7-dichlorofluorescein diacetate (DCFH-DA), propidium iodide (PI), and thiazolyl blue tetrazlium bromide (MTT) were obtained from Sigma Aldrich (St. Louis, MO, USA).

\section{Analysis of cell metabolic activity}

RL95-2 $\left(8 \times 10^{3}\right)$ and HEC-1-A $\left(5 \times 10^{3}\right)$ cells were seeded into 96-well plates and incubated in their respective media. The next day, they were exposed to the indicated drugs in fresh DMEM/F12 or McCoy's $5 \mathrm{~A}$ medium for the indicated periods. MTT solution $(0.5 \mathrm{mg} / \mathrm{mL}$ in phosphate buffered saline (PBS)) was then added to each well, and the cells were incubated for $4 \mathrm{~h}$ at $37^{\circ} \mathrm{C}$. After removing the supernatants, dimethyl sulfoxide (DMSO; $100 \mu \mathrm{L}$ ) was added to dissolve the precipitate, and the absorbances at 570 $\mathrm{nm}$ and $650 \mathrm{~nm}$ were measured using an enzyme-linked immunosorbent assay plate reader (Multiskan EX, Thermo Fisher Scientific). The relative metabolic activity was calculated based on the absorbance ratio between cells cultured with the indicated drugs and the untreated controls, which were assigned a value of 100. A combination index $(\mathrm{Cl})$ was also calculated using CalcuSyn (Biosoft, Cambridge, UK) to produce an isobologram where a $\mathrm{Cl}<1$ indicates a synergistic combination effect and a $\mathrm{Cl}>1$ indicates an antagonistic combination effect (Chou, 2006).

\section{Western blot analysis}

RL95-2 and HEC-1-A cells were lysed in radio-immunoprecipitation assay buffer (100 mM Tris- $\mathrm{HCl}(\mathrm{pH}$ 8.0), $150 \mathrm{mM} \mathrm{NaCl}, 0.1 \%$ SDS, and $1 \%$ Triton 100) at $4{ }^{\circ} \mathrm{C}$. Proteins in the resultant lysates were separated by sodium dodecyl sulfate polyacrylamide gel electrophoresis, after which the resolve proteins were immunoblotted with antibodies against $\beta$-actin, p53, p62, FAS, nuclear factor-erythroid factor 2-related factor 2 (Nrf2) (Santa Cruz Biotechnology, Santa Cruz, CA, USA), phospho-histone H3 (H3P; serine phosphorylation at residue 10), histone $H 3(H 3)$, microtubule-associated proteins $1 A / 1 B$ light chain $3 B$ (LC3B), phospho-acetyl-CoA carboxylase (p-ACC; serine phosphorylation at residue 79), ACC, cleaved polyADP-ribose polymerase (cPARP), CHOP (Cell Signaling, Danvers, MA, USA), phospho-histone H2A.X 
(YH2A.X; serine phosphorylation at residue 139), Cyclin D1 (Abcam, Cambridge, UK), and heme oxygenase 1 (HO-1) (Enzo Life Sciences, Farmingdale, NY, USA).

\section{Cell cycle profiles and cellular proliferation analysis}

RL95-2 $\left(6 \times 10^{5}\right)$ and HEC-1-A $\left(3 \times 10^{5}\right)$ cells were seeded into 6-well plates in their respective media. The next day, the indicated drugs were added in fresh medium, and the cells were incubated for an additional 24 or $48 \mathrm{~h}$. For cell cycle analysis, the cells were fixed in $70 \%$ ice-cold ethanol and stored at $-20^{\circ} \mathrm{C}$ overnight. The fixed cells were then centrifuged (1,000 rpm, $5 \mathrm{~min})$, washed twice with ice-cold PBS supplemented with $1 \% \mathrm{FBS}$, and stained with PI solution $(5 \mu \mathrm{g} / \mathrm{mL}$ PI in PBS, $0.5 \%$ Triton $\mathrm{x}-100$, and 0.5 $\mu \mathrm{g} / \mathrm{mL}$ RNase A) for $30 \mathrm{~min}$ at $37^{\circ} \mathrm{C}$ in the dark. For each condition, 10,000 cells were analyzed using a flow cytometer (BD FACSCalibur ${ }^{\mathrm{TM}}$ ) and Cell Quest Pro software (BD Biosciences, Franklin Lakes, NJ, USA).

For cell proliferation assays, following the incubation protocol described above, the cells were incubated for an additional $1 \mathrm{~h}$ with $10 \mathrm{mM}$ BrdU (BD Pharmingen BrdU Flow Kit, San Diego, CA, USA). The medium was then discarded, and the cells were fixed at room temperature for 30 min and treated with FITC-conjugated anti-BrdU antibody (BD Pharmingen). After washing, the cells were incubated with 7-AAD and analyzed using a BD FACSCalibur ${ }^{\mathrm{TM}}$ flow cytometer and Cell Quest Pro software (BD Biosciences).

\section{Apoptosis analysis}

For apoptosis assays, the cells were stained with Annexin V-PE and 7-AAD and then detected with flow cytometry using the manufacturer's protocol (BD PharMingen, San Diego, CA, USA). Briefly, after treatment with the indicated drugs, cells were washed twice with ice-cold PBS and stained with $5 \mu \mathrm{l}$ of Annexin V-PE and $10 \mu \mathrm{l}$ of 7-AAD $(5 \mu \mathrm{g} / \mathrm{ml})$ in $1 \mathrm{ml}$ of binding buffer for $15 \mathrm{~min}$ at room temperature in the dark. Apoptotic cells were then counted using a BD FACSCalibur ${ }^{\text {TM }}$ flow cytometer and Cell Quest Pro software (BD Biosciences, Franklin Lakes, NJ, USA).

\section{ROS assay}

The DCFH-DA fluorescent marker was used to identify intracellular ROS levels. In addition, MitoSOX ${ }^{\mathrm{TM}}$ Red (Invitrogen, Carlsbad, CA, USA) is a fluorescent dye that reacts selectively with mitochondrial superoxide in live cells. Cells were incubated for $1.5 \mathrm{~h}$ with selected doses of palmitate and then stained with DCFHDA $(10 \mathrm{mM})$ or MitoSOX ${ }^{\mathrm{TM}}$ Red $(10 \mathrm{mM})$ in serum-free medium for $30 \mathrm{~min}$ at $37^{\circ} \mathrm{C}$ and harvested. Samples were then evaluated using a FACSCalibur flow cytometer and Cell Quest Pro software (BD Biosciences, Franklin Lakes, NJ, USA).

\section{Mitochondrial membrane potential analysis}

RL95-2 $\left(6 \times 10^{5}\right)$ and HEC-1-A $\left(3 \times 10^{5}\right)$ cells were seeded into 6-well plates in their respective media. The next day, selected doses of palmitate were added in fresh medium, and the cells were incubated for an 
additional 24 or $48 \mathrm{~h}$. All dead and viable cells were then harvested, washed with PBS and incubated with $1 \mathrm{x}$ binding buffer containing the MMP-sensitive fluorescent dye JC- 1 for $30 \mathrm{~min}$ at $37^{\circ} \mathrm{C}$ in the dark. The cells were then washed twice with PBS, resuspended in $500 \mu \mathrm{L}$ of $1 \mathrm{x}$ binding buffer and analyzed using a FACSCalibur flow cytometer and Cell Quest Pro software (BD Biosciences, Franklin Lakes, NJ, USA).

\section{Immunocytochemistry}

Immunocytochemical analysis was carried out with cells adhering to cover slips in 24-well plates. After treatment with selected doses of palmitate for $1.5 \mathrm{~h}$, the cells were fixed for $10 \mathrm{~min}$ in $4 \%$ formaldehyde, incubated for $10 \mathrm{~min}$ in $0.1 \%$ Triton X-100 solution, washed 3 times in PBS, and treated for $1 \mathrm{~h}$ at room temperature with $1 \%$ BSA. Thereafter, the cells were incubated with anti-TOM20 antibody at $4{ }^{\circ} \mathrm{C}$ overnight. The next day, the cells were washed with PBS and incubated for $1 \mathrm{~h}$ with FITC. Cell nuclei were stained by DAPI. Mitochondrial morphology was observed using a THUNDER Imager microscope equipped with a $100 \times$ objective (Leica, Germany).

\section{Mitochondrial mass assay}

RL95-2 $\left(6 \times 10^{5}\right)$ and HEC-1-A $\left(3 \times 10^{5}\right)$ cells were seeded into 6-well plates in their respective media. The next day, the cells were treated with selected doses of palmitate for $1.5 \mathrm{~h}$ and stained with $20 \mathrm{nM}$ MitoView ${ }^{\mathrm{TM}}$ Green (Biotium, CA, USA) for $30 \mathrm{~min}$ at $37^{\circ} \mathrm{C}$ in the dark. Samples were then evaluated using a FACSCalibur flow cytometer and Cell Quest Pro software (BD Biosciences, Franklin Lakes, NJ, USA).

\section{Statistical analysis}

Values were expressed as the mean \pm SD from at least three independent experiments. All comparisons between groups were made using Student's t-tests. Statistical significance: n.s., not significant, * $p<0.05$; ** $p<0.01 ; * \star \star p<0.001$.

\section{Results}

\section{Palmitate cytotoxicity in human endometrial cancer cell lines.}

We first examined the cytotoxicity of palmitate toward the RL95-2 (type I) and HEC1A (type II) endometrial cancer cell lines. The two cell lines were incubated for 24 or $48 \mathrm{~h}$ with increasing doses of palmitate, and cytotoxicity was detected with MTT conversion assays (Fig. 1A and B). Our preliminary data showed that RL95-2 cells were more sensitive to palmitate than HEC-1-A cells. Consistent with that observation, the ED50 for palmitate toxicity was estimated to be $69.51 \mathrm{mM}$ in RL95-2 treated for $24 \mathrm{~h}$ and $56.89 \mathrm{mM}$ for HEC1A cells treated for $48 \mathrm{~h}$.

To better understand the mechanism underlying palmitate cytotoxicity, we examined its effect on the levels of various proteins. Western blot analysis showed that levels of FAS, p53, cyclin D1 (a cell cycle G1 biomarker), and the ratio of phosphorylated to total ACC (fatty acid synthesis biomarker) were all significantly and dose-dependently decreased in both RL95-2 and HEC-1-A cells (Fig. 1C). The H3P/H3 
ratio, a cell cycle G2/M biomarker, was difficult to determine because $\mathrm{H} 3$ and $\mathrm{H} 3 \mathrm{P}$ proteins were both dose-dependently elevated in RL95-2 cells. At higher doses, palmitate also induced expression of $\mathrm{yH} 2 \mathrm{~A} . \mathrm{x}$ (a DNA damage biomarker) and dosedependently increased p62 levels and the LC3B II/I ratio (two autophagy biomarkers). The effect of palmitate on levels of Nrf2 and HO-1 (anti-ROS stress biomarkers) differed between RL95-2 and HEC-1-A cells; whereas their levels were dose-dependently increased in RL95-2 cells, they were decreased in HEC-1A cells. Overall, responsiveness to palmitate was more apparent in RL95-2 than HEC-1A cells.

\section{Synergistic effects of palmitate and chemotherapeutic drugs in human endometrial cancer cell lines.}

To test whether palmitate has synergistic effects with conventional chemotherapeutic agents, we applied the Chou-Talalay method to calculate the Cls and dosage requirements of palmitate with cisplatin or doxorubicin in RL95-2 and HEC1A cells. Consistent with the greater drug sensitivity of RL95-2 cells, the dose of cisplatin or doxorubicin combined with palmitate was significantly lower in RL952 than HEC-1-A cells (Fig. 2). For palmitate with cisplatin, the $\mathrm{Cl}$ was $<1$ in both RL952 and HEC-1-A cells, indicating synergistic effects. On the other hand, for palmitate with doxorubicin, the $\mathrm{Cl}$ was $<1$ only in HEC-1-A cells. A significant synergistic effect was observed when palmitate was combined with cisplatin at concentrations ranging from $4.5 \mathrm{mM}$ to $53.4 \mathrm{mM}$ (Fig. 2B).

Molecular mechanisms of palmitate and chemotherapeutic drugs in human endometrial cancer cell lines.

We next investigated the effects of combination therapy on levels of various proteins in RL95-2 and HEC1-A cells. In RL95-2 cells, cisplatin and doxorubicin individually increased $\gamma H 2 A . x, p 53$, and H3, and their abilities to increase levels of $\mathrm{YH} 2 \mathrm{~A} . \mathrm{x}, \mathrm{p} 53, \mathrm{LC} 3 \mathrm{~B}, \mathrm{CHOP}$ and cleaved PARP were all enhanced by palmitate (Fig. 3A). Conversely, palmitate downregulated the effects of cisplatin and doxorubicin on FAS, HO-1 and the $\mathrm{p}-\mathrm{ACC} / \mathrm{ACC}$ and $\mathrm{H} 3 \mathrm{P} / \mathrm{H} 3$ ratios in RL95-2 cells. In HEC-1-A cells, palmitate downregulated the effects of cisplatin and doxorubicin on $\mathrm{p} 53$ and the $\mathrm{PACC} / \mathrm{ACC}$ and $\mathrm{H} 3 \mathrm{P} / \mathrm{H} 3$ ratios, whereas it enhanced their effects on LC3B, CHOP and cleaved PARP (Fig. 3B). These results indicate that the mechanisms by which palmitate acts in combination with chemotherapy drugs differ in RL95-2 and HEC-1A cells.

\section{Effects of palmitate and chemotherapeutic drugs on the cell cycle profile, cellular proliferation, and apoptosis in human endometrial cancer cell lines.}

Because palmitate induced downregulation of cyclin D1, a cell cycle-related protein, in both RL95-2 and HEC-1-A cells and also significantly induced H3 and H3P (a cell cycle G2/M biomarker) in RL95-2 cells (Fig. 1B), we used PI staining to test the effect of palmitate on cell cycle profiles in RL95-2 and HEC-1-A cells. In both RL95-2 and HEC-1-A cells, palmitate significantly induced cell cycle arrest in the subG1 and G2/M phases and inhibited the S phase (Fig. 4A and B). Moreover, combining cisplatin or doxorubicin with palmitate enabled us to verify the cell cycle changes they reportedly induce in cancer cells (Fig. 4C and $4 \mathrm{D}$ for cisplatin; $4 \mathrm{E}$ and $4 \mathrm{~F}$ for doxorubicin). It is well-known that cisplatin works on $\mathrm{G} 1$ populations (Wagner, et al., 2009), while doxorubicin works on the G2/M population (Ling, et al., 1996). We found that in RL95-2 cells, combined treatment with palmitate and cisplatin increased the population at sub-G1 
phase, whereas the combined treatment with doxorubicin decreased the subG1 phase population. In HEC1-A cells, for palmitate in combination with cisplatin or doxorubicin, the subG1 phase tended to increase, which is consistent with the results summarized in Figs. 2 and 3 and points to a synergistic effect of the combined therapy in HEC-1-A cells. Given the finding that palmitate significantly reduced the numbers of cells at S-phase (Fig. 4A and 4B), we used BrdU staining to assess palmitate effects on cell proliferation. Our results showed that palmitate significantly and dose-dependently reduces cell proliferation capability in RL95-2 and HEC-1-A cells (Fig. 5A and B).

To determine whether palmitate-induced cytotoxicity and the elevation in subG1 populations leads to increased apoptosis among RL95-2 and HEC-1-A cells, we used Annexin V-PE and 7-AAD labelling to quantitatively assess cellular apoptosis. After palmitate treatment, the early and late apoptotic cell populations were increased significantly among both RL95-2 and HEC-1-A cells (Fig. 6A and B). Cisplatin and doxorubicin each increased the early and late apoptotic populations among RL95-2 cells, but cisplatin only increased the early and late apoptotic populations in HEC-1-A cells (Fig. 6C and D). Synergistic effects on total (early plus late) apoptotic populations were observed when RL95-2 and HEC1-A cells were treated with palmitate plus cisplatin or doxorubicin. In RL95-2 cells, the synergistic effect with cisplatin was in the early apoptotic population, while the synergistic effect with doxorubicin was in both the early and late apoptotic populations. In HEC-1-A cells, the synergistic effect with cisplatin was in the late apoptotic population, while the synergistic effect with doxorubicin was in the early and late apoptotic populations.

\section{Effects of palmitate and chemotherapeutic drugs on mitochondrial function in human endometrial cancer cell lines.}

Mitochondria play key roles in cellular survival, ROS generation, and stressinduced programmed cell death. Moreover, recent studies suggest ROS are involved in palmitate-induced apoptosis (Liu, et al., 2015, Wei, et al., 2013, Zhang, et al., 2017). We therefore assessed ROS levels in palmitate-treated RL95-2 and HEC-1-A cells. We found that whether using DCFH-DA to measure overall cell ROS levels or MitoSox to measure mitochondrial superoxide, ROS levels declined as the palmitate concentration increased in both RL95-2 and HEC-1-A cells (Fig. 7A-D). $\mathrm{H}_{2} \mathrm{O}_{2}$, which served as a positive control, significantly increased ROS levels in our two assays.

Because loss of MMP is a hallmark of apoptosis activation (Henry-Mowatt, et al., 2004), we used JC-1 dye to measure changes in MMP after palmitate treatment in RL95-2 and HEC-1-A cells (Fig. 8A and B). The results revealed that palmitate dose-dependently reduced MMP in both RL95-2 and HEC-1-A cells.

Mitochondrial morphology is dynamic, as the organelles continually undergo fission and fusion in response to their environmental conditions (Youle, et al., 2012). When cells sense mild stress, mitochondria form an elongated and interconnected network to increase ATP production. Under severe cellular stress, however, mitochondria divide into fragments for mitophagy or apoptosis. MitoView ${ }^{\mathrm{TM}} \mathrm{Green}$ is a green fluorescent mitochondrial dye, the signal from which is based on mitochondrial mass rather 
than mitochondrial membrane potential. We used immunofluorescent staining with TOM20 and Mitoview $^{\text {TM }}$ Green to evaluate the effect of palmitate on mitochondrial morphology and mass in RL95-2 and HEC-1-A cells (Fig. 9A and B). The results showed that palmitate not only triggered mitochondrial fragmentation in both RL95-2 and HEC-1-A cells, it also decreased mitochondrial mass. These findings suggest that palmitate causes mitochondrial damage in RL95-2 and HEC-1-A cells.

\section{Discussion}

In this work, we found that palmitate may increase the sensitivity of endometrial cancer cells to chemotherapy drugs. Our findings suggest it significantly increased cell cycle arrest, DNA damage, autophagy, and apoptosis in RL95-2 and HEC-1-A cells, with RL95-2 cells being more sensitive to palmitate than HEC-1-A cells. An earlier study of the metabolic profiles of seven endometrial cancer cell lines revealed that RL95-2 and HEC-1-A cells depend on different metabolic pathways (Byrne, et al., 2014). The extracellular acidification rate; oxidation of glucose, glutamine, and palmitate; and DNL from glucose, glutamine, and acetate were all higher in RL95-2 than HEC-1-A cells. Notably, RL95-2 cells were the most dependent on DNL pathways among the seven endometrial cancer cell lines tested. We suggest that this may explain why RL95-2 cells are more sensitive to palmitate than are HEC1A cells.

The overall purpose of this study was to investigate the impact and underlying mechanisms of palmitate in two types of endometrial cancer. Known as the "triple endometrial cancer syndrome," obesity, diabetes and hypertension often co-exist in patients with endometrial cancer (Yang, et al., 2019). Recent studies indicate that palmitate levels are increased in cerebrospinal fluid from overweight and obese individuals and correlate positively with body mass index and abdominal circumference (Melo, et al., 2020). Elevation of palmitate in cerebrospinal fluid was also seen in overweight people with diabetes, dyslipidemia, and/or hypertension. One study reported that enzymes catalyzing glycolysis and DNL, including ACC1, ACC2 and FAS, are upregulated in most endometrial tumor tissues as compared to adjacent nonmalignant tissues (Byrne, et al., 2014). Overexpression of FAS has been detected during the early stages of cancer development, is more pronounced in more advanced tumors, and is typically associated with a poor prognosis (Lupu, et al., 2006). Recent findings have also shown that FAS blockade decreases cell proliferation and viability by stimulating apoptosis in endometrial carcinoma cells (Menendez, et al., 2004). In addition to FAS, our present findings demonstrate that palmitate directly downregulates ACC and H3 protein levels. Details of the mechanisms remain to be investigated in the future, however.

Results from several studies have led to differing conclusions about the properties of palmitate. Several studies have reported that palmitate exhibits potential tumorigenic properties (Kim, et al., 2019, Nath, et al., 2021, Pan, et al., 2019), though they also reported that it exhibits anticancer activity. In a study of hepatocellular carcinoma cells, for example, palmitate reduced cell membrane fluidity and limited glucose metabolism to enhance the anticancer effect of methylseleninic acid (Lin, et al., 2017). In breast cancer, palmitate induces a different transcription program, reducing expression of HER2 and HER3, thereby sensitizing the cells to trastuzumab (Baumann, et al., 2016). In the present study, therefore, palmitate was 
used as an adjuvant to increase the sensitivity of endometrial cancer cells to chemotherapy drugs in a manner that provides a potential therapeutic strategy for the treatment of endometrial cancer.

We also observed that palmitate induces mitochondrial fragmentation and MMP disruption that did not appear to be triggered by an increase in ROS. In fact, palmitate decreased levels of cellular ROS in both RL95-2 and HEC-1-A cells, which differs from reports indicating that palmitate lipotoxicity is mediated by increases in ROS (Egnatchik, et al., 2014, Lee, et al., 2018, Liu, et al., 2015). On the other hand, our results are consistent with a report showing that palmitate-induced apoptosis is not dependent on ROS (HicksonBick, et al., 2002). In addition, another report showed that the antioxidant Nacetylcysteine or reduction of glutathione offer only limited protection to pancreatic $b$ cells against palmitate-induced death (Choi, et al., 2011). Instead, it appears that palmitate causes a loss of MMP, which may lead to mitochondrial dysfunction, a decrease of b-oxidation, and eventually a reduction in ROS, though that has yet to be tested.

\section{Conclusion}

Our findings indicate that palmitate exhibits potential anti-endometrial cancer activity, especially in HEC1-A cells, which are type II endometrial cancer cells and therefore less sensitive to chemotherapy. Palmitate administered as an adjuvant treatment significantly increased cancer cell sensitivity to cisplatin and doxorubicin. This study thus provides a potential therapeutic strategy for the treatment of endometrial cancers otherwise resistant to treatment.

\section{Abbreviations}

ACC: acetyl-CoA carboxylase; ACLY: ATP- citrate lyase; CHOP : C/EBP homologous protein; Cl: combination index; cPARP: cleaved poly-ADP-ribose polymerase; DCFH-DA: 2',7-dichlorofluorescein diacetate; DMSO: dimethyl sulfoxide; DNL: de novo lipogenesis; ED50: median effective dose; ER: endoplasmic reticulum; FAS: fatty acid synthase; FBS: fetal bovine serum; H3P: phospho-histone H3; H3: histone H3; HO-1: heme oxygenase 1; LC3B: microtubule-associated proteins 1A/1B light chain 3B; MMP: mitochondrial membrane potential; MTT: thiazolyl blue tetrazlium bromide; Nrf2: nuclear factor-erythroid factor 2-related factor 2; PBS: phosphate buffered saline; PI: propidium iodide; ROS: reactive oxygen species; TCA: tricarboxylic acid.

\section{Declarations}

\section{Acknowledgments}

Not applicable.

\section{Author's contributions}


Z.S. Wu: Data curation, Formal analysis, Investigation, Validation, Writing - original draft. S.M. Huang: Conceptualization, Formal analysis, Methodology, Project administration, Supervision, Writing - original draft. Y.C. Wang: Conceptualization, Formal analysis, Funding acquisition, Supervision, Writing - review \& editing.

\section{Funding}

This work was supported by grants from the Ministry of Science and Technology [MOST-109-2221-E016-002-MY3 to Y-C WANG], Taiwan, Republic of China.

\section{Availability of data and materials}

The authors confirm the availability of all data generated or analyzed in this manuscript.

\section{Ethics approval and consent to participate}

Not applicable.

\section{Consent for publication}

Not applicable.

\section{Competing interests}

The authors declare that they have no conflict of interest.

\section{Author details}

${ }^{1}$ Graduate Institute of Life Sciences, National Defense Medical Center, Taipei City 114, Taiwan.

${ }^{2}$ Department of Biochemistry, National Defense Medical Center, Taipei City 114, Taiwan.

${ }^{3}$ Department of Obstetrics and Gynecology, Tri-Service General Hospital, National Defense Medical Center, Taipei City 114, Taiwan.

\section{References}

1. Torre LA, Islami F, Siegel RL, Ward EM, Jemal A. Global Cancer in Women: Burden and Trends. Cancer Epidemiol Biomarkers Prev. 2017;26:444-57.

2. Tseng CJ, Lu CJ, Chang CC, Chen GD, Cheewakriangkrai C. Integration of Data Mining Classification Techniques and Ensemble Learning to Identify Risk Factors and Diagnose Ovarian Cancer Recurrence. Artif Intell Med. 2017;78:47-54.

3. Felix AS, Brinton LA. Cancer Progress and Priorities: Uterine Cancer. Cancer Epidemiol Biomarkers Prev. 2018;27:985-94. 
4. Sherman ME. Theories of Endometrial Carcinogenesis: A Multidisciplinary Approach. Mod Pathol. 2000;13:295-308.

5. Murali R, Soslow RA, Weigelt B. Classification of Endometrial Carcinoma: More Than Two Types. Lancet Oncol. 2014;15:e268-78.

6. Cosgrove CM, Barrington D, Backes FJ. Impact of Molecular Classification on Treatment Paradigms in Uterine Cancers. Curr Oncol Rep. 2021;23:75.

7. Ly LD, et al. Oxidative Stress and Calcium Dysregulation by Palmitate in Type 2 Diabetes. Exp Mol Med. 2017;49:e291.

8. Song Z, Xiaoli AM, Yang F. Regulation and Metabolic Significance of De Novo Lipogenesis in Adipose Tissues. Nutrients. 2018;10.

9. Song X, et al. Dietary Long-Chain Fatty Acids and Carbohydrate Biomarker Evaluation in a Controlled Feeding Study in Participants from the Women's Health Initiative Cohort. Am J Clin Nutr. 2017;105:1272-82.

10. Carta G, Murru E, Banni S, Manca C. Palmitic Acid: Physiological Role, Metabolism and Nutritional Implications. Front Physiol. 2017;8:902.

11. Wilke MS, et al. Synthesis of Specific Fatty Acids Contributes to VIdl-Triacylglycerol Composition in Humans with and without Type 2 Diabetes. Diabetologia. 2009;52:1628-37.

12. Davis JE, Gabler NK, Walker-Daniels J, Spurlock ME. The C-Jun N-Terminal Kinase Mediates the Induction of Oxidative Stress and Insulin Resistance by Palmitate and Toll-Like Receptor 2 and 4 Ligands in 3t3-L1 Adipocytes. Horm Metab Res. 2009;41:523-30.

13. Xu S, et al. Palmitate Induces Er Calcium Depletion and Apoptosis in Mouse Podocytes Subsequent to Mitochondrial Oxidative Stress. Cell Death Dis. 2015;6:e1976.

14. Sato Y, et al. Palmitate Induces Reactive Oxygen Species Production and B-Cell Dysfunction by Activating Nicotinamide Adenine Dinucleotide Phosphate Oxidase through Src Signaling. J Diabetes Investig. 2014;5:19-26.

15. Joseph LC, et al. Inhibition of Napdh Oxidase 2 (Nox2) Prevents Oxidative Stress and Mitochondrial Abnormalities Caused by Saturated Fat in Cardiomyocytes. PLoS One. 2016;11:e0145750.

16. Yamagishi S, et al. Palmitate-Induced Apoptosis of Microvascular Endothelial Cells and Pericytes. Mol Med. 2002;8:179-84.

17. Brodeur MR, Bouvet C, Barrette M, Moreau P. Palmitic Acid Increases Medial Calcification by Inducing Oxidative Stress. J Vasc Res. 2013;50:430-41.

18. Meyn RE, Jenkins WT, Murray D. Radiation Damage to DNA in Various Animal Tissues: A Comparison of Yields and Repair in Vivo and in Vitro. Basic Life Sci. 1986;38:151-8.

19. Choi SE, et al. Stimulation of Lipogenesis as Well as Fatty Acid Oxidation Protects against PalmitateInduced Ins-1 Beta-Cell Death. Endocrinology. 2011;152:816-27.

20. Baumann J, Wong J, Sun Y, Conklin DS. Palmitate-Induced Er Stress Increases Trastuzumab Sensitivity in Her2/Neu-Positive Breast Cancer Cells. BMC Cancer. 2016;16:551. 
21. Hardy S, et al. Saturated Fatty Acid-Induced Apoptosis in Mda-Mb-231 Breast Cancer Cells. A Role for Cardiolipin. J Biol Chem. 2003;278:31861-70.

22. Byrne FL, et al. Metabolic Vulnerabilities in Endometrial Cancer. Cancer Res. 2014;74:5832-45.

23. Chou TC. Theoretical, Basis. Experimental Design, and Computerized Simulation of Synergism and Antagonism in Drug Combination Studies. Pharmacol Rev. 2006;58:621-81.

24. Wagner JM, Karnitz LM. Cisplatin-Induced DNA. Damage Activates Replication Checkpoint Signaling Components That Differentially Affect Tumor Cell Survival. Mol Pharmacol. 2009;76:208-14.

25. Ling YH, el-Naggar AK, Priebe W, Perez-Soler R. Cell Cycle-Dependent Cytotoxicity, G2/M Phase Arrest, and Disruption of P34cdc2/Cyclin B1 Activity Induced by Doxorubicin in Synchronized P388 Cells. Mol Pharmacol. 1996;49:832-41.

26. Liu J, et al. Palmitate Promotes Autophagy and Apoptosis through Ros-Dependent Jnk and P38 Mapk. 2015;463:262-67.

27. Wei CD, Li Y, Zheng HY, Tong YQ. Dai WJMmr. Palmitate Induces H9c2 Cell Apoptosis by Increasing Reactive Oxygen Species Generation and Activation of the Erk1/2 Signaling Pathway. 2013;7:85561.

28. Zhang Y, et al. Palmitate Induces Vsmc Apoptosis Via Toll Like Receptor (TIr) 4/Ros/P53 Pathway. 2017;263:74-81.

29. Henry-Mowatt J, Dive C, Martinou JC, James D. Role of Mitochondrial Membrane Permeabilization in Apoptosis and Cancer. Oncogene. 2004;23:2850-60.

30. Youle RJ, van der Bliek AM. Mitochondrial Fission, Fusion, and Stress. Science. 2012;337:1062-5.

31. Yang X, Wang J. The Role of Metabolic Syndrome in Endometrial Cancer: A Review. Front Oncol. 2019;9:744.

32. Melo HM, et al. Palmitate Is Increased in the Cerebrospinal Fluid of Humans with Obesity and Induces Memory Impairment in Mice Via Pro-Inflammatory Tnf-A. Cell Rep. 2020;30:2180-94.e8.

33. Lupu R, Menendez JA. Targeting Fatty Acid Synthase in Breast and Endometrial Cancer: An Alternative to Selective Estrogen Receptor Modulators? Endocrinology. 2006;147:4056-66.

34. Menendez JA, et al. Inhibition of Tumor-Associated Fatty Acid Synthase Activity Antagonizes Estradiol-and Tamoxifen-Induced Agonist Transactivation of Estrogen Receptor (Er) in Human Endometrial Adenocarcinoma Cells. 2004;23:4945-58.

35. Kim S, et al. Dietary Palmitate Cooperates with Src Kinase to Promote Prostate Tumor Progression. Prostate. 2019;79:896-908.

36. Nath A, et al. Palmitate-Induced Ire1-Xbp1-Zeb Signaling Represses Desmoplakin Expression and Promotes Cancer Cell Migration. Mol Cancer Res. 2021;19:240-48.

37. Pan J, Dai Q, Zhang T, Li C. Palmitate Acid Promotes Gastric Cancer Metastasis Via Fabp5/Sp1/Uca1 Pathway. Cancer Cell Int. 2019;19:69.

38. Lin L, et al. Functional Lipidomics: Palmitic Acid Impairs Hepatocellular Carcinoma Development by Modulating Membrane Fluidity and Glucose Metabolism. Hepatology. 2017;66:432-48. 
39. Egnatchik RA, Leamy AK, Noguchi Y, Shiota M, Young JDJM. Palmitate-Induced Activation of Mitochondrial Metabolism Promotes Oxidative Stress and Apoptosis in H4iiec3 Rat Hepatocytes. 2014;63:283-95.

40. Lee SW, et al. Palmitate Induces Lipoapoptosis in Schwann Cells through Ros Generation-Mediated Stamp2 Downregulation. Biochem Biophys Res Commun. 2018;503:1260-66.

41. Hickson-Bick DL, Sparagna GC, Buja LM, McMillin JB. Palmitate-Induced Apoptosis in Neonatal Cardiomyocytes is Not Dependent on the Generation of Ros. Am J Physiol Heart Circ Physiol. 2002;282:H656-64.

\section{Figures}




\section{Figure1}

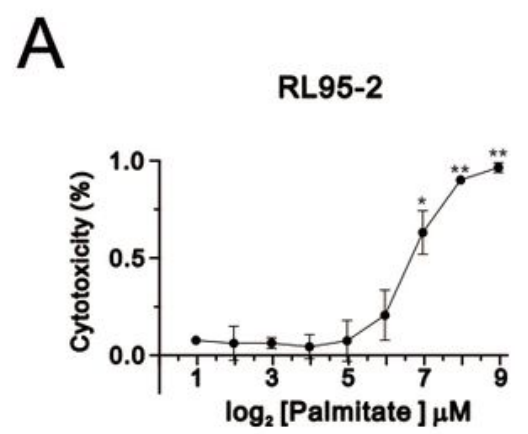

C

RL95-2
Palmitate, $\mu \mathrm{M}$

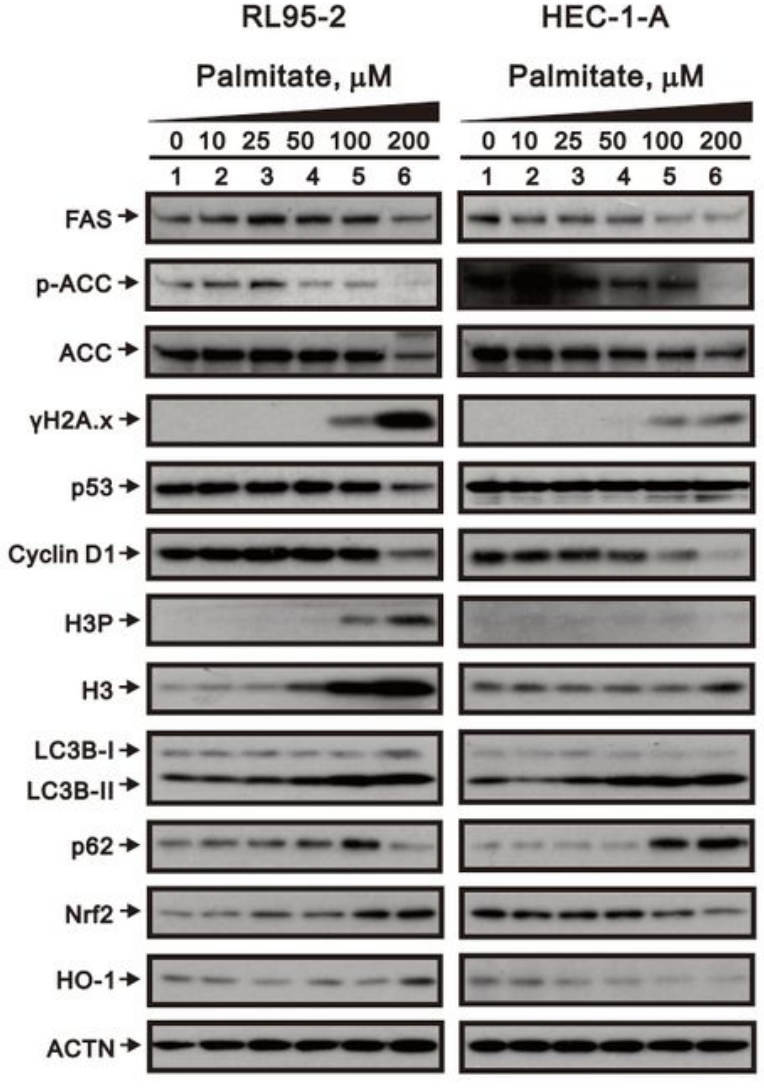

HEC-1-A

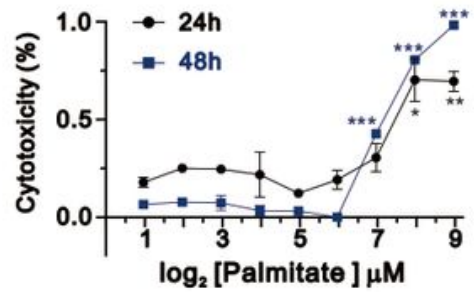

HEC-1-A

Palmitate, $\mu \mathrm{M}$

\section{Figure 1}

Responsiveness of human endometrial carcinoma cells to palmitate. A-B Cell viability measured using the MTT method. RL95-2, and HEC-1-A cells were treated for $24 \mathrm{~h}$ or $48 \mathrm{~h}$ with palmitate $(0,1.953125$, $3.90625,7.8125,15.625,31.25,62.5,125,250,500 \mathrm{mM})$. Symbols depict the mean \pm SD of three independent experiments. ${ }^{*} p<0.05$, $* \star p<0.01$, and $* \star \star ~ p<0.001$ (Student's t-tests). C RL95-2, and HEC1 -A cells were treated for $24 \mathrm{~h}$ with indicated concentrations of palmitate. Cell lysates were subjected to 
western blot analysis using antibodies against the indicated proteins. Alpha actinin (ACTN) was the loading control.

\section{Figure 2}

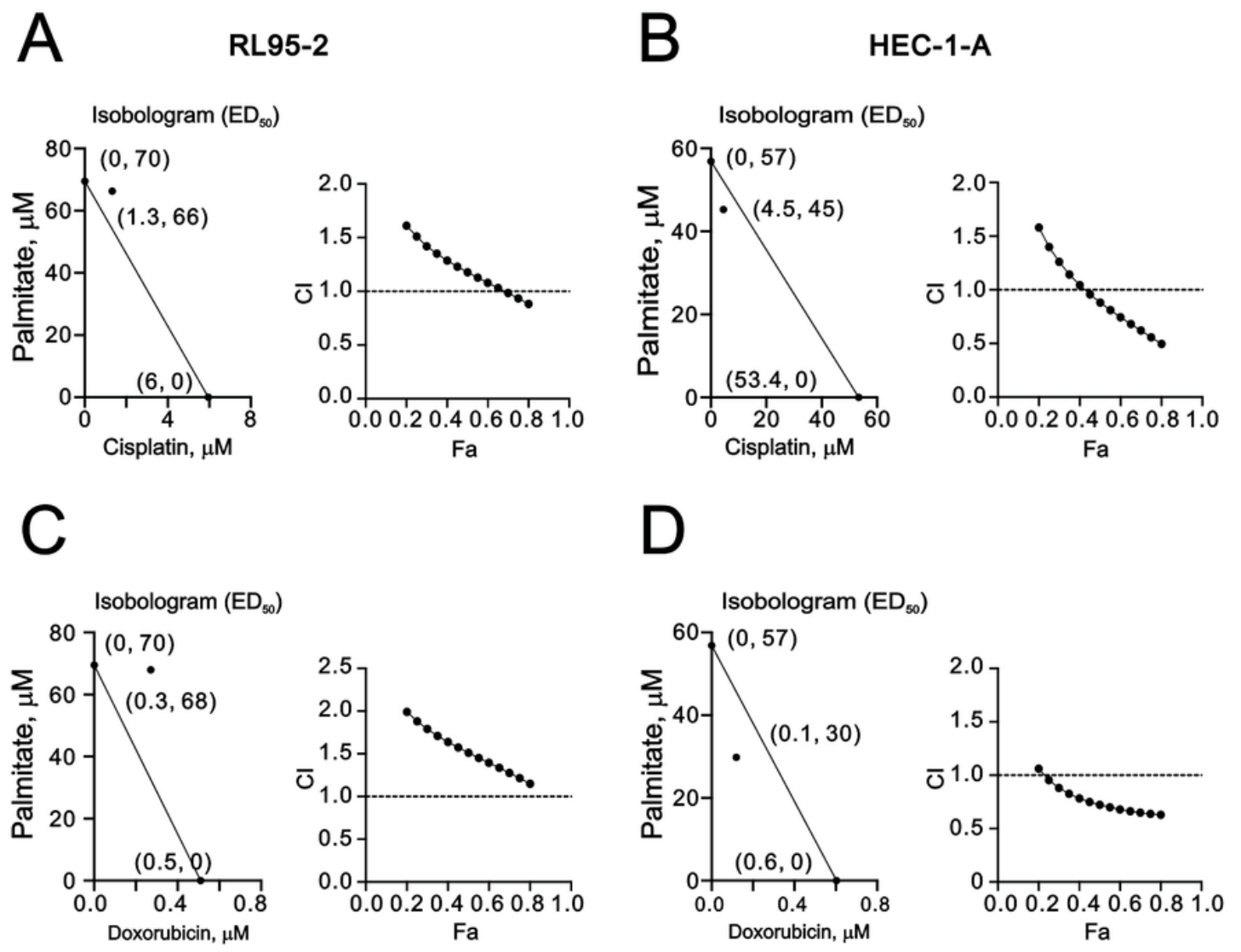

\section{Figure 2}

Combination indexes for palmitate with cisplatin or doxorubicin in RL95-2 and HEC-1-A cells. A,C RL95-2 cells were treated for $24 \mathrm{~h}$ with palmitate $(0,1.953125,3.90625,7.8125,15.625,31.25,62.5,125,250,500$ $\mathrm{mM})$ combined with cisplatin $(0,0.3125,0.625,1.25,2.5,5,10,20 \mathrm{mM})$ or doxorubicin $(0,0.0625,0.125$, $0.25,0.5,1,2 \mathrm{mM})$. B,D HEC-1-A were treated for $24 \mathrm{~h}$ or $48 \mathrm{~h}$ with palmitate $(0,1.953125,3.90625$, $7.8125,15.625,31.25,62.5,125,250,500 \mathrm{mM})$ combined with cisplatin $(0,1.5625,3.125,6.25,12.5,25$, $50,100 \mathrm{mM})$ or doxorubicin $(0,0.0625,0.125,0.25,0.5,1,2 \mathrm{mM})$. Cell viability was measured using the MTT method. Isobolograms (ED50) were calculated using CalcuSyn software. 


\section{Figure 3}

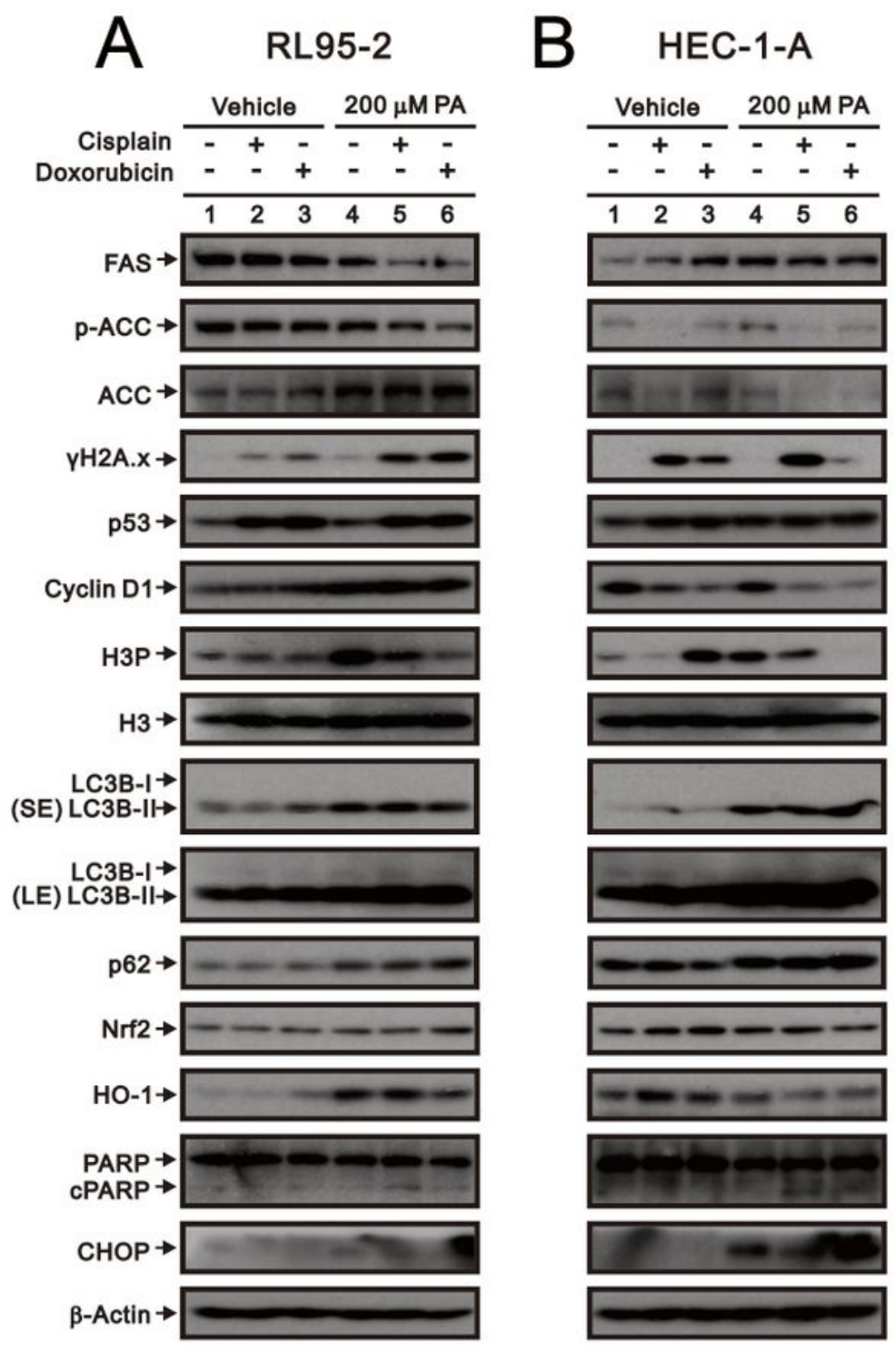

Figure 3

Effects of palmitate with cisplatin or doxorubicin on protein expression in RL95-2 and HEC-1-A cells. A RL95-2 cells were incubated for $24 \mathrm{~h}$ with $200 \mathrm{mM}$ palmitate plus $5 \mathrm{mM}$ cisplatin or $0.5 \mathrm{mM}$ doxorubicin. B HEC-1-A cells were incubated for $24 \mathrm{~h}$ with $200 \mathrm{mM}$ palmitate plus $50 \mathrm{mM}$ cisplatin or $0.5 \mathrm{mM}$ doxorubicin. Cell lysates were subjected to western blot analysis using antibodies against the indicated proteins. $b$-actin was the loading control. 


\section{Figure 4}

A

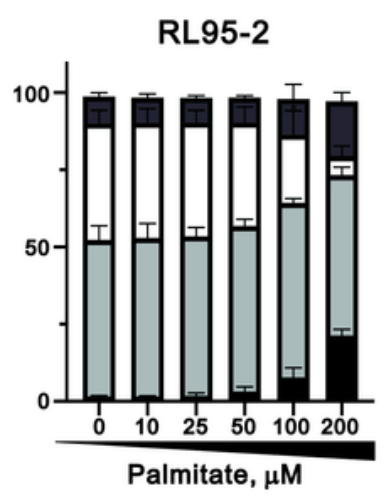

C

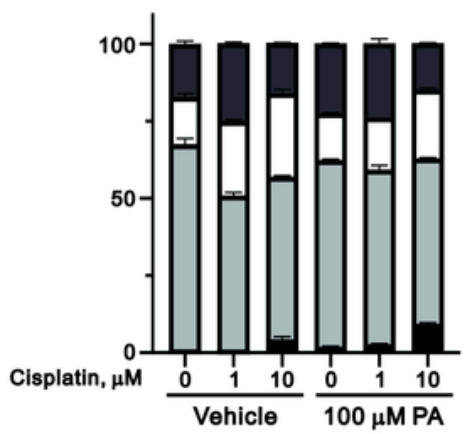

$E$

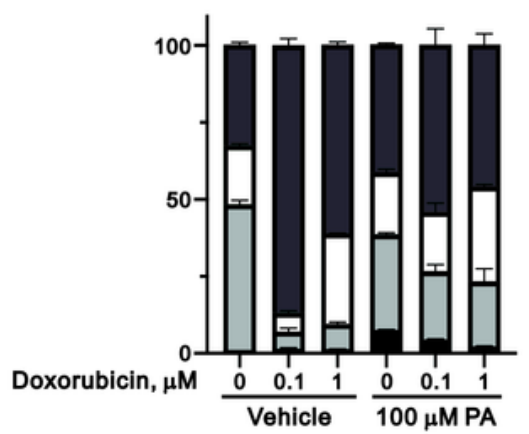

B HEC-1-A

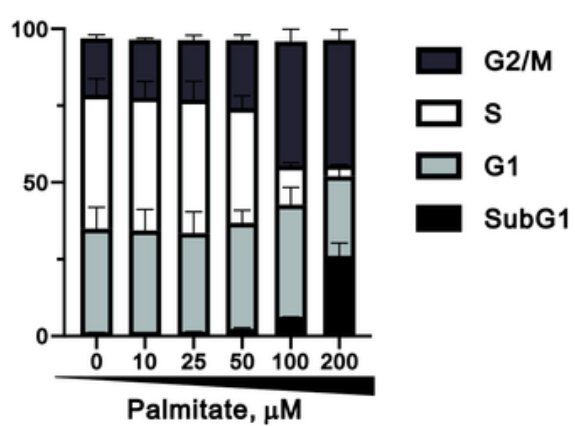

D

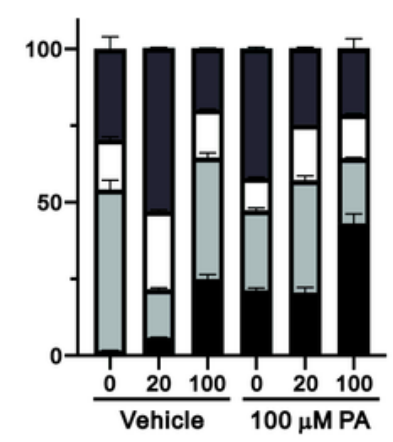

$\mathrm{F}$

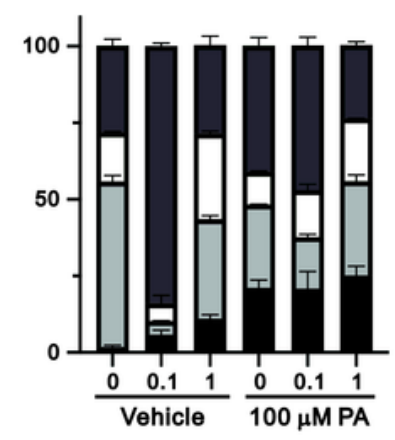

Figure 4

Effect of palmitate alone and in combination with cisplatin or doxorubicin on the cell cycle profiles in human endometrial cancer cells. A, C, E RL95-2 and B, D, F HEC-1-A cells were incubated for 24 h, after which they were treated with the indicated concentrations of doxorubicin or cisplatin plus $100 \mathrm{mM}$ palmitate for 24 or $48 \mathrm{~h}$. Cell cycle profiles were then analyzed using flow cytometry. Bars depict the mean \pm SD of three independent experiments. 


\section{Figure 5}
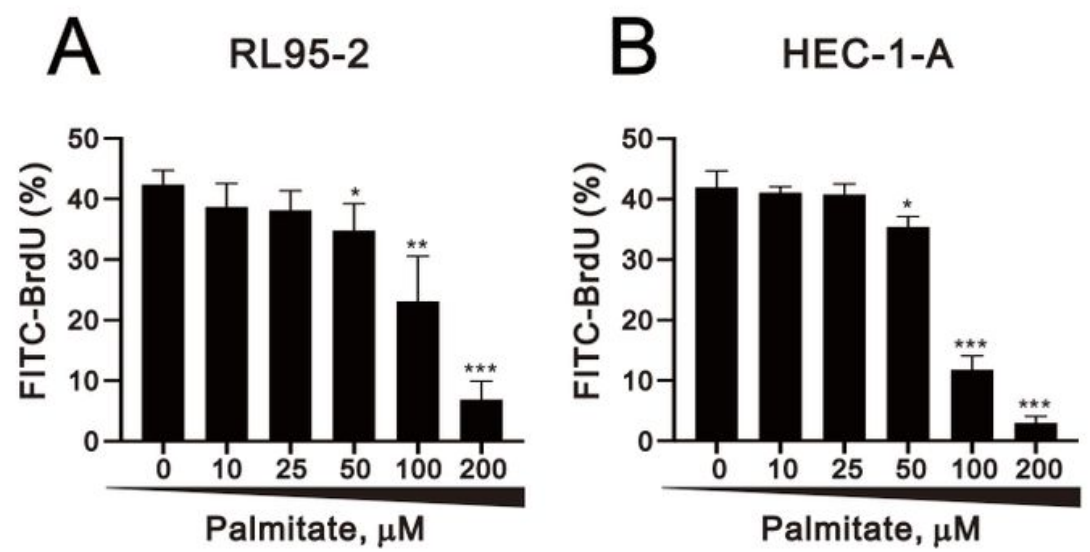

\section{Figure 5}

Effect of palmitate on proliferation of human endometrial cancer cells. A RL95-2 and B HEC-1-A cells were incubated for $24 \mathrm{~h}$, after which they were treated for 24 or $48 \mathrm{~h}$ with the indicated concentrations of palmitate. Cell proliferation indicated by BrdU incorporation was analyzed using flow cytometry. Bars depict the mean \pm SD of three independent experiments. ${ }^{*} p<0.05,{ }^{* \star} p<0.01$, and ${ }^{* \star *} p<0.001$ (Student's t-tests). 


\section{Figure 6}

\section{A RL95-2}

Palmitate, $\mu \mathrm{M}$

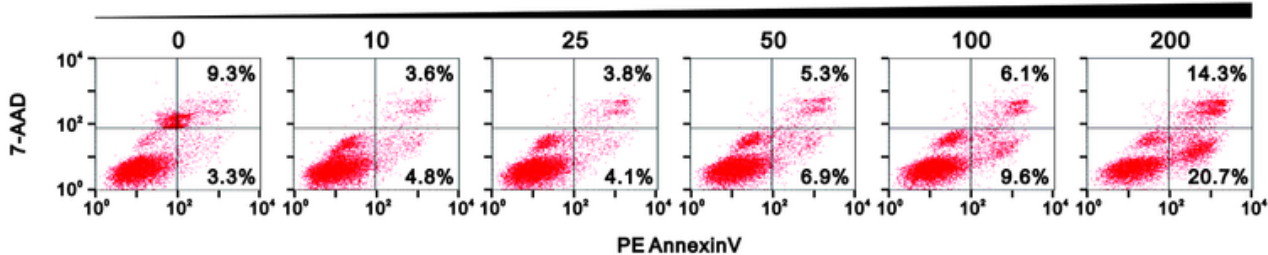

B HEC-1-A

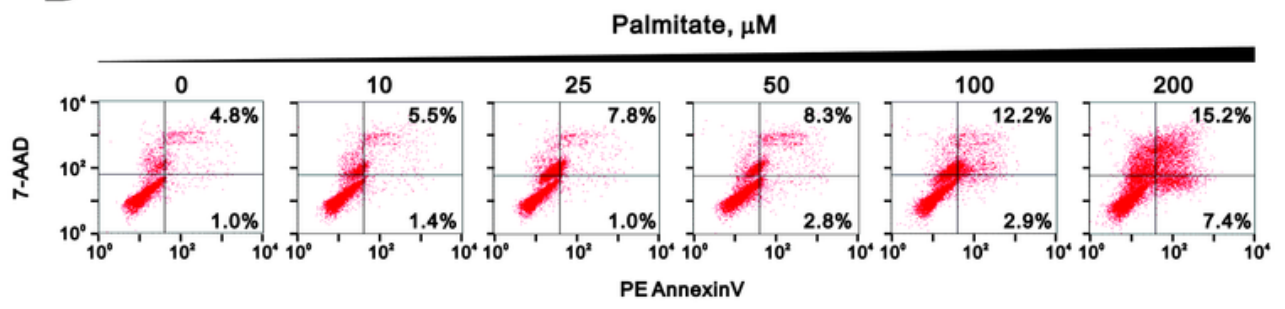

$C^{\text {RL95-2 }}$

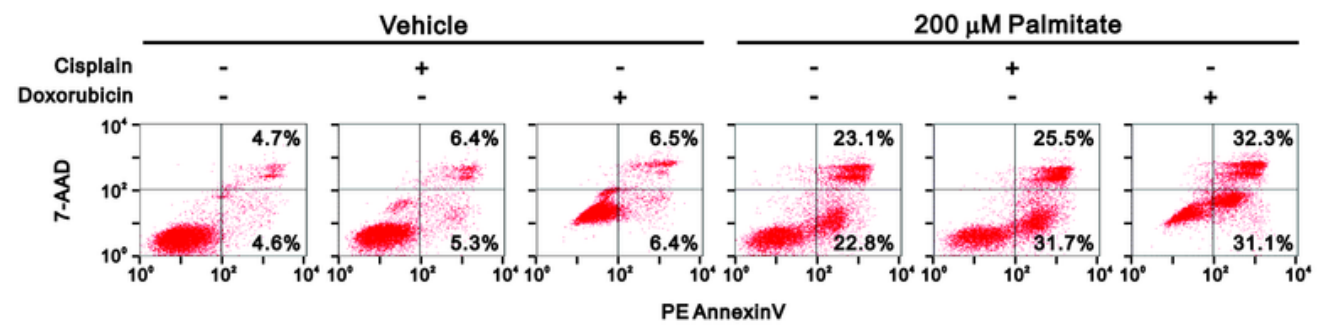

D HEC-1-A

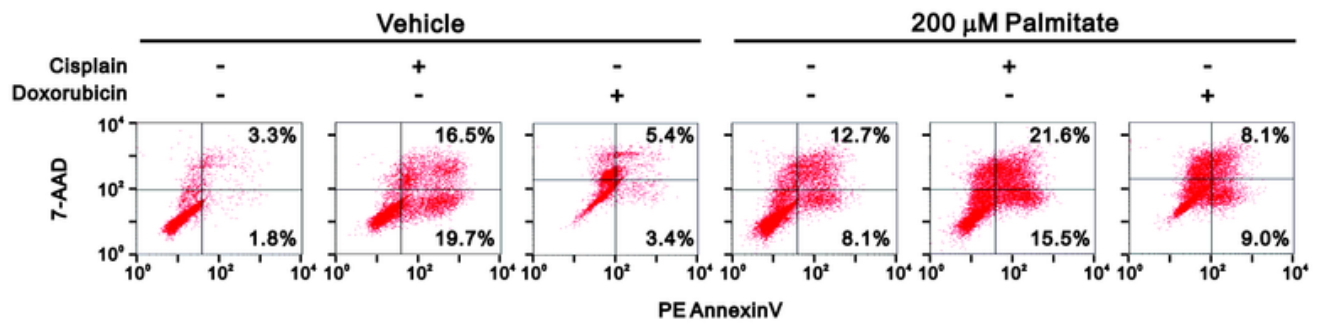

\section{Figure 6}

Effect of palmitate alone and in combination with cisplatin or doxorubicin on apoptosis among human endometrial cancer cells. A RL95-2 and B HEC-1-A cells were incubated for $24 \mathrm{~h}$, after which they were treated for 24 or $48 \mathrm{~h}$ with palmitate $(0,10,25,50,100,200 \mathrm{mM})$. C RL95-2 cells treated for $24 \mathrm{~h}$ with 5 $\mathrm{mM}$ cisplatin or $0.5 \mathrm{mM}$ doxorubicin plus $200 \mathrm{mM}$ palmitate. D HEC-1-A cells treated for $48 \mathrm{~h}$ with $50 \mathrm{mM}$ 


\section{Figure 7}

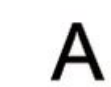

RL95-2
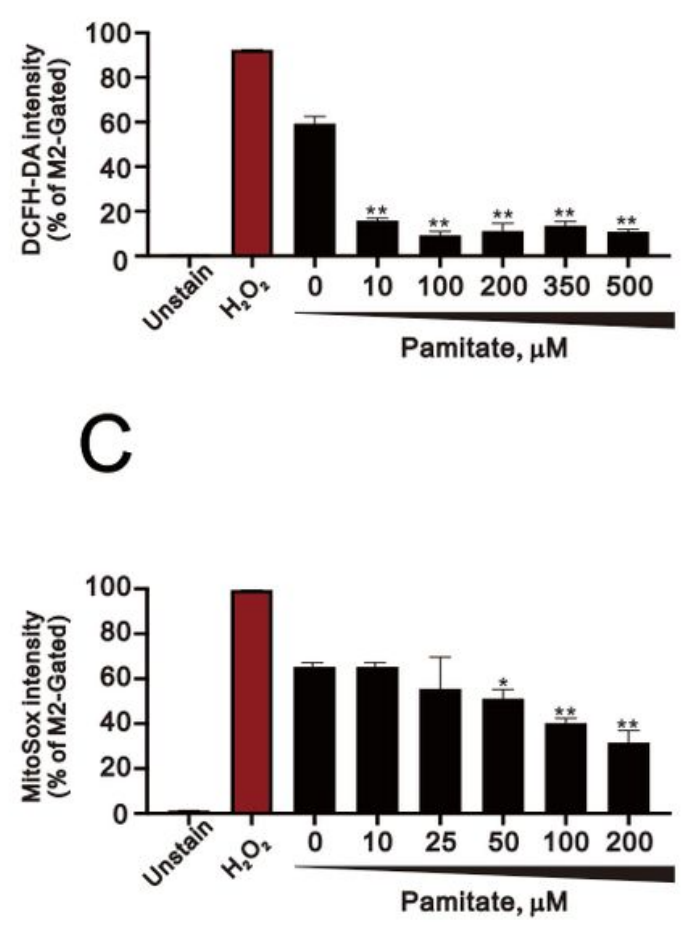

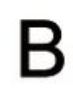

HEC-1-A
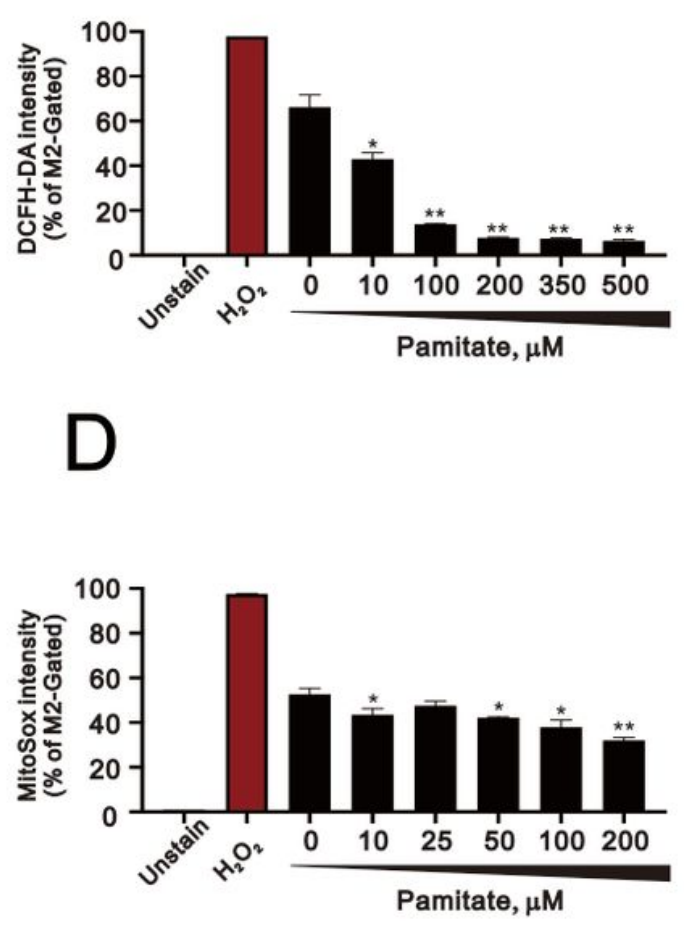

\section{Figure 7}

Effects of palmitate on ROS levels in human endometrial cancer cells. A RL95-2 and B HEC-1-A cells were incubated for $24 \mathrm{~h}$, after which they were treated for $1.5 \mathrm{~h}$ with the indicated concentration of palmitate. Cellular ROS levels were monitored using 10 mM DCFH-DA with flow cytometry. C RL95-2 and D HEC-1-A cells were incubated for $24 \mathrm{~h}$, after which they were treated for $1.5 \mathrm{~h}$ with the indicated concentration of palmitate. Mitochondrial ROS levels were monitored using $5 \mathrm{mM}$ MitoSOX with flow cytometry. $\mathrm{H} 2 \mathrm{O} 2$ serves as a positive control in all panels. Bars depict the mean \pm SD of three independent experiments. ${ }^{*} p$ $<0.05,{ }^{\star} * \mathrm{p}<0.01$, (Student's t-tests). 


\section{Figure 8}

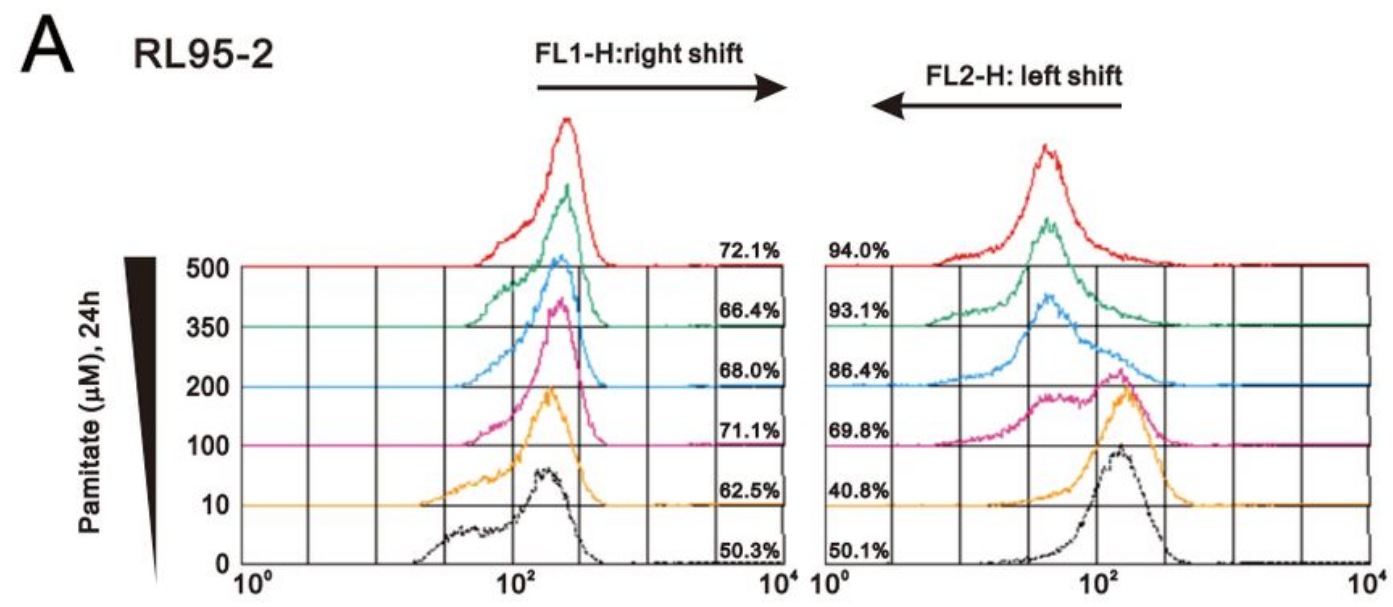

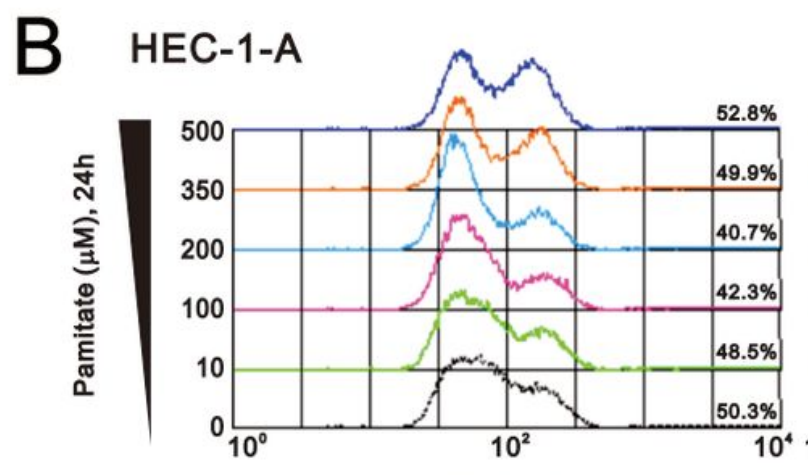

FL1-H

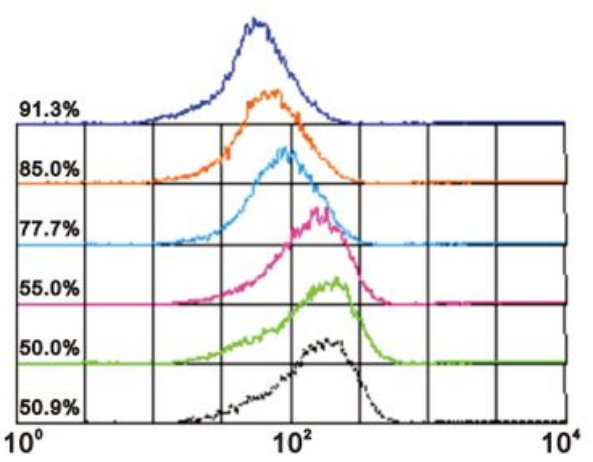

FL2-H

\section{Figure 8}

Effects of palmitate on mitochondrial membrane potential in human endometrial cancer cells. A RL95-2 and B HEC-1-A cells were incubated for $24 \mathrm{~h}$, treated for $24 \mathrm{~h}$ with the indicated concentration of palmitate, and stained for 15 min with JC-1 dye. Mitochondrial membrane potential was detected using flow cytometry. Traces shown are representative of three independent experiments. 


\section{Figure 9}

A RL95-2

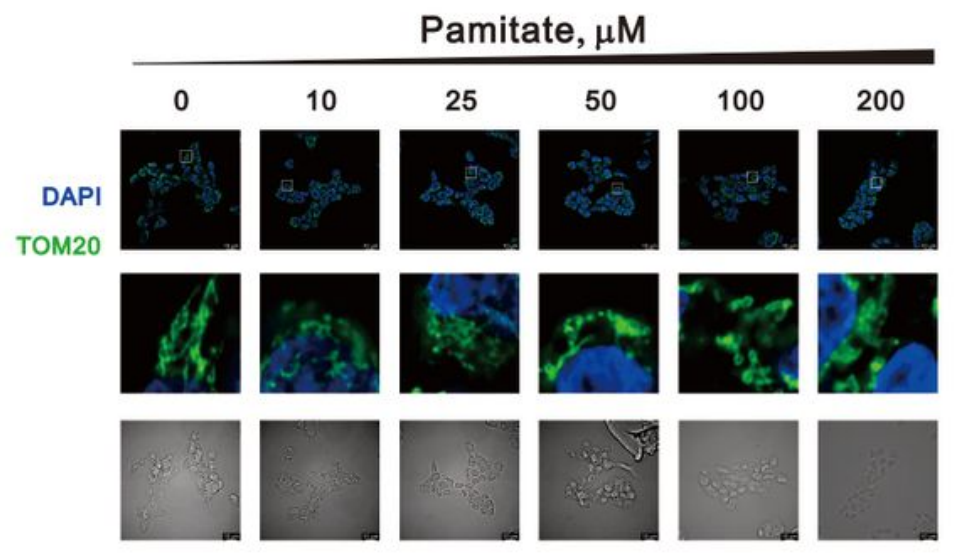

B HEC-1-A

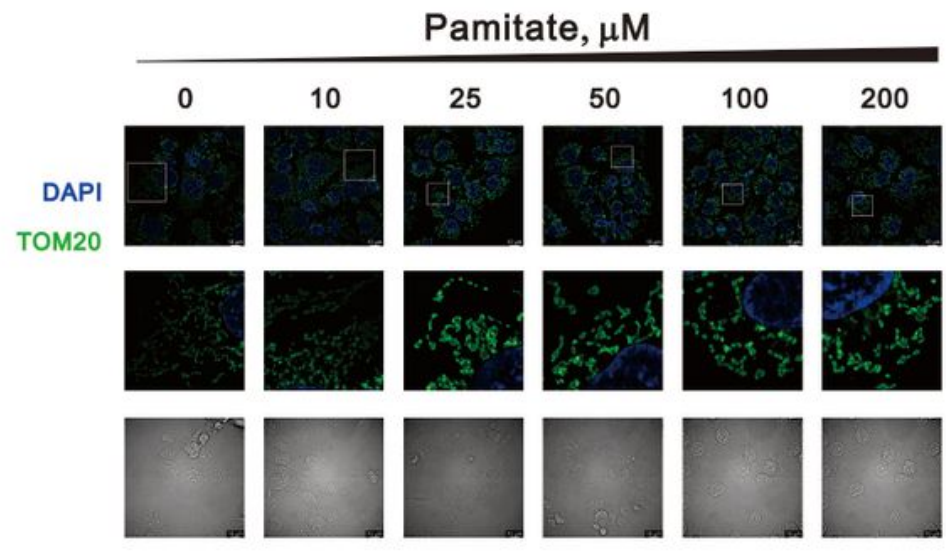

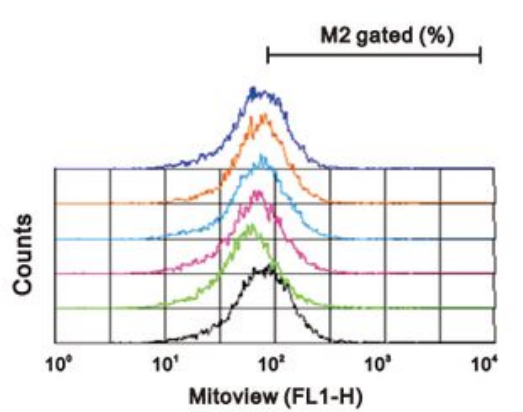
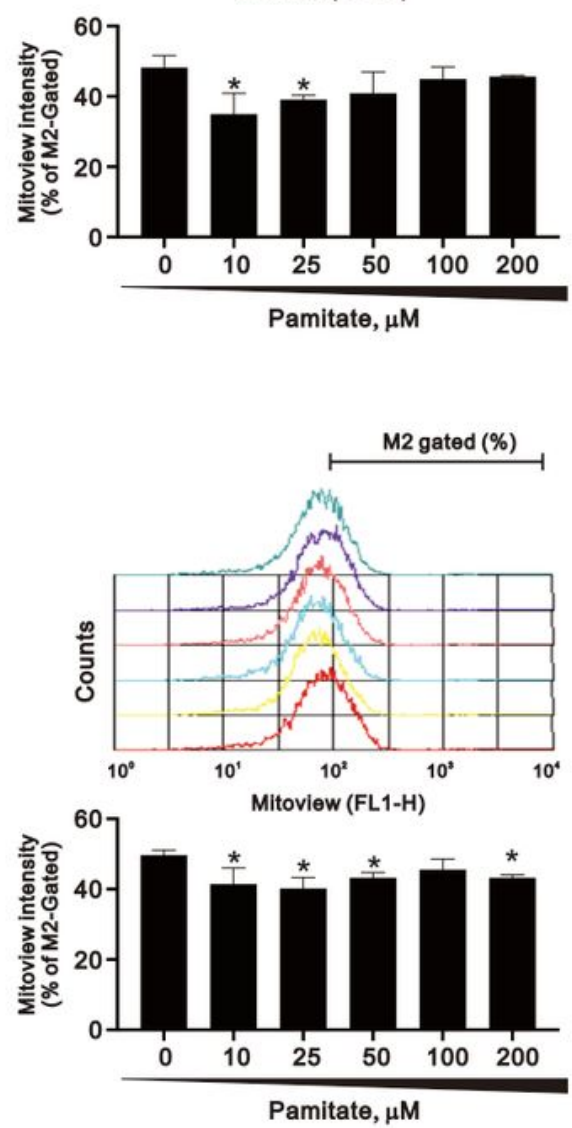

\section{Figure 9}

Effects of palmitate on mitochondrial morphology in human endometrial cancer cells. A RL95-2 and B HEC-1-A cells were treated for $1.5 \mathrm{~h}$ with the indicated concentrations of palmitate, after which they immunostained for TOM20 (mitochondria, green). Nuclei were stained with 4',6-diamidino-2-phenylindole (DAPI, blue). Images were obtained using a Leica THUNDER Imager microscope (100x oil-immersion objective). Mitochondrial mass was assayed using MitoViewTM Green with flow cytometry. Traces are 
representative of three independent experiments. Bars depict the mean \pm SD of three independent experiments. ${ }^{\star} p<0.05$ (Student's t-tests). 